
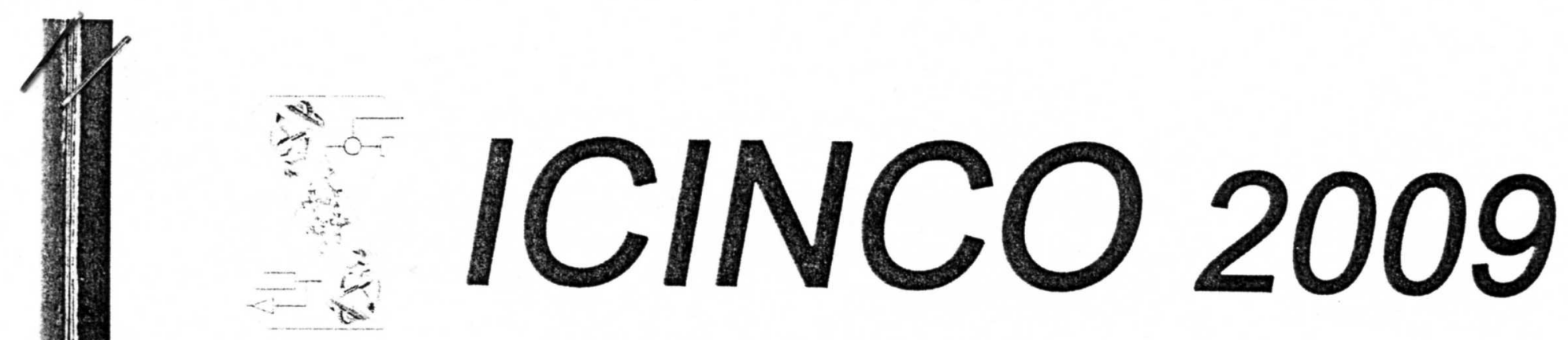

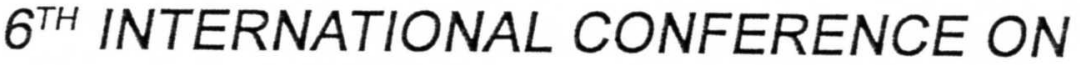

INFORMATICS IN CONTROL, AUTOMATION AND ROBOTICS

\title{
Final Program and Book of Abstracts
}

MILAN - ITALY · JULY 2 - 5, 2009

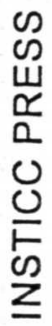

IN COOPERATION WITH

IIISTICC

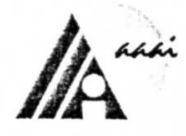

CO-SPONSORED BY

IFAC 
get a constant value of moisture of the grain. At the same time, these data have been used to obtain a total traceability of the process.

Paper 170

10:45 - 11:15

Poster Session 3

Lobby

\section{PROSPECTIVE ELASTO-PLASTIC PRESSURE SENSORS}

All-Elasto-Plastic Polyisoprene/Nanostructured Carbon Pressure Sensing Element

Maris Knite, Juris Zavickis, Gatis Podins, Raimonds Orlovs and Kaspars Ozols

Riga Technical University, Riga, Lithuania

Keywords: Completely Flexible Pressure Sensor, Polyisoprene, High-Structured Carbon Black, Hybrid
Composite.

Abstract: Our further achievements in the design, processing and studies of physical properties of elastomer - nano-structured carbon composites as prospective compressive strain sensor materials for robotic tactile elements as well as for other automatic systems are presented. Composites made of polyisoprene matrix and high-structure carbon nanoparticle filler have been designed and manufactured to develop polymer nano-composites for flexible, entirely polymeric pressure sensing elements. Electrical resistance of the composites as a function of mechanical strain and pressure is studied. SEM pictures of cross-section surface of sensing elements are analyzed.

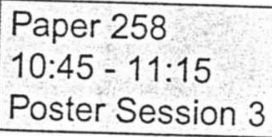

\section{INTEGRATING REUSABLE CONCEPTS INTO A REFERENCE ARCHITECTURE DESIGN OF} COMPLEX EMBEDDED SYSTEMS

\section{Liliana Dobrica}

University Politehnica of Bucharest, Bucharest, Romania

Keywords: Embedded systems, Software architecture, Reference architecture, Patterns, Quality.

Abstract: The content of this paper addresses the issues regarding integrating reusable concepts for a quality-based design of reference architecture in the context of complexity that is specific to today's embedded control systems. The reference architecture consists of core services and is designed based on considering taxonomy of requirements and constraints, reusable control patterns and a qualitybased measurement instrument.
Paper 321

10:45 - 11:15

Poster Session 3

Lobby

\section{PERFORMANCE EVALUATION OF A MODIFIED SUBBAND NOISE CANCELLATION SYSTEM IN A NOISY ENVIRONMENT}

\author{
Ali O. Abid Noor, Salina Abdul Samad and Aini \\ Hussain \\ University Kebangsaan Malaysia - UKM, Malaysia
} Keywords: Noise Cancellation, Adaptive Filtering,
Filter Banks. Abstract: This paper presents a subband noise
canceller with reduced residual noise. The canceller is developed by modifying and optimizing an existing multirate filter bank that is used to improve the performance of a conventional fullband adaptive filtering. The proposed system is aimed to overcome problems of slow asymptotic convergence and high residual noise incorporating with the use of oversampled filter banks for acoustic noise cancellation applications. Analysis and synthesis filters are optimized for minimum amplitude distortion. The proposed scheme offers a simplified structure that without employing cross adaptive filters or stop band filters reduces the effect of coloured components near the band edges in the frequency response of the analysis filters. Issues of increasing convergence speed and decreasing the residual noise at the system output are addressed. Performance under white and coloured environments is evaluated in terms of mean square error MSE performance. Fast initial convergence was obtained with this modification. Also a decrease in the amount of residual noise by approximately $10 \mathrm{~dB}$ compared to an equivalent subband model without modification was reachable under actual speech and background noise.

\begin{tabular}{|ll|}
\hline Paper 348 & \\
10:45 $-11: 15$ & Lobby \\
Poster Session 3 & \\
\hline
\end{tabular}

\section{MAPPING DEVELOPMENT OF MES FUNCTIONALITIES}

\author{
Vladimír Modrák \\ Technical University of Košice, Slovak Republic \\ Ján Mandulák \\ LPH Vranov N/T, S.R.O., Slovak Republic
}

Keywords: Manufacturing management, Information system, Interface, functionality.

Abstract: This paper presents a view on MES and ERP functional areas in a hierarchy of enterprise 